\title{
Importance of an extensive examination in case of fetal death
}

\author{
Lavezzi AM \\ "Lino Rossi" Research Center for the study and prevention of unexpected perinatal death and SIDS - Department of Biomedical, \\ Surgical and Dental Sciences, University of Milan, Italy. anna.lavezzi@unimi.it
}

I refer to the valuable article of Saboori et al recently published on Bratisl Med J (2016; 117: 80-86) related to genetic polymorphisms in recurrent spontaneous abortion, to point out some considerations and provide new insight that might be of interest to readers.

Fetal deaths are the most common adverse pregnancy outcomes and the leading contributor to perinatal mortality in developed countries. The detection of the pathogenetic mechanism, even more if the death in uterus is recurrent, is very important, above all to introduce preventive measures and thus decrease the incidence of prenatal mortality.

There are wide-ranging reasons why a fetus may die spontaneously. These reasons generally include, besides genetic factors, placental insufficiency, infections, fetal malformations and health problems of the mother.

In case of intrauterine death, in addition to genetic studies, the primary fundamental step of investigation must be the autoptic examination, as worldwide recognized. Unfortunately, in about one-third to half of fetal losses, after the autopsy, the cause of death cannot be determined. It is important, above all in these cases, to perform a deep examination of the autonomic nervous system, that could highlight subtle developmental alterations of neuronal structures, mostly included in the brainstem, checking the basic vital functions (1).

In addition, in case of fetal death, even more if recurrent and/ or unexplained, the collection and analysis of the clinical history, with particular reference to the maternal lifestyle, and the main potential risk factors (such as maternal smoking, alcohol and drug abuse and also air pollution in the mother's area of residence) is very important.

In particular, maternal smoking during pregnancy is widely recognized as highly associated with fetal death. The mothers must be asked for information about their smoking habit before and during pregnancy, and possibly, their answer should be validated through toxicological examinations of cotinine, the main stable metabolite of nicotine.

Recently, original investigations have demonstrated the involvement of persistent pollutants such as: pesticides and insecticides, a category of harmful agents belonging to the "endocrine disrupting compounds" (i.e. exogenous substances able to alter the functions of the endocrine system and, consequently, to affect the whole organism) in the etiology of sudden fetal death (2-4). Traces of highly toxic chemicals, as organochlorine and organophosphate pesticides ( $\alpha$ and $\gamma$-chlordane, chlorfenvinfos, chlorpyrifos, $p, p-D D T, p, p-D D E$, endrin, $\alpha$ - and $\beta$-endosulfans) had been directly detected in brain samples of fetuses, died in agricultural areas where they were used.

Then, in addition to an albeit important genetic analysis in case of spontaneous abortion, an extensive study according to the above reported indications is very essential and not just to give an explanation to parents, but above all to allow the planning of an effective prevention.

\section{References}

1. Lavezzi AM, Ferrero S, Matturri L, Roncati L, Pusiol T. Developmental neuropathology of brainstem respiratory centers in unexplained stillbirth: What's the meaning? Int J Dev Neurosci 2016; 53: 99-106.

2. Pusiol T, Lavezzi A, Matturri L, Termopoli V, Cappiello A, Piscioli F et al. Impact assessment of endocrine disruptors on sudden intrauterine and infant death syndromes. Eur J Forensic Sci 2016; 3: 8-15.

3. Roncati L, Termopoli V, Pusiol T. Negative Role of the Environmental Endocrine Disruptors in the Human Neurodevelopment. Front Neurol 2016; 7: 143.

4. Roncati L, Piscioli F, Pusiol T. The endocrine disruptors among the environmental risk factors for stillbirth. Sci Total Environ 2016; 563-564, 1086-1087.
Received November 2, 2016. Accepted December 1, 2016.

Department of Biomedical, Surgical and Dental Sciences, University of Milan, Italy

Address for correspondence: A.M. Lavezzi, “Lino Rossi-Research Center for the study and prevention of sudden perinatal death and SIDS"

Phone: +39.02 .50320821 , Fax: +39.02 .50320823$ 